\title{
Pitfalls on sample preparation for ex vivo imaging of resected cancer tissue using enzyme-activatable fluorescent probes
}

\author{
Ai Mochida ${ }^{1, *}{ }^{,}$Fusa Ogata ${ }^{1, *}$, Yasuhiro Maruoka ${ }^{1}$, Tadanobu Nagaya ${ }^{1}$, Ryuhei Okada $^{1}$, \\ Fuyuki Inagaki ${ }^{1}$, Daiki Fujimura ${ }^{1}$, Peter L. Choyke ${ }^{1}$ and Hisataka Kobayashi ${ }^{1}$ \\ ${ }^{1}$ Molecular Imaging Program, Center for Cancer Research, National Cancer Institute, National Institutes of Health, Bethesda, \\ Maryland, United States of America \\ * These authors have contributed equally to this work \\ Correspondence to: Hisataka Kobayashi, email: kobayash@mail.nih.gov \\ Keywords: fluorescence-guided surgery; activatable probe; enzyme; ex vivo imaging; temperature \\ Received: September 25, $2018 \quad$ Accepted: October 22, $2018 \quad$ Published: November 13, 2018 \\ Copyright: Mochida et al. This is an open-access article distributed under the terms of the Creative Commons Attribution License \\ 3.0 (CC BY 3.0), which permits unrestricted use, distribution, and reproduction in any medium, provided the original author and \\ source are credited.
}

\section{ABSTRACT}

In vivo and ex vivo fluorescence imaging-assisted surgery can aid in determining the margins of tumors during surgical resection. While a variety of fluorescent probes have been proposed for this task, small molecule enzyme-activatable fluorescent probes are ideal for this application. They are quickly activated at tumor sites and result in bright signal with little background, resulting in high sensitivity. Testing in resected specimens, however, can be difficult. Enzymes are usually stable after freezing and thawing but catalytic reactions are generally temperature-dependent. Therefore, tissue sample temperature should be carefully considered. In this study two enzyme activatable probes, $\gamma$-glutamylhydroxymethyl rhodamine green (gGlu-HMRG) that reacted with $\gamma$-glutamyltransferase and SPIDER- $\beta$ Gal that reacted with $\beta$-galactosidase, were employed to determine the effects of temperature on fluorescence signal kinetics in both fresh and frozen and then thawed ex vivo experimental ovarian cancer tissue samples. The results suggest $\gamma$-glutamyltransferase was less sensitive to temperature than $\beta$-galactosidase. Fresh samples showed higher fluorescence signals of gGluHMRG compared with thawed samples likely because the freeze-thaw cycle decreased the rate of internalization of the activated probe into the lysosome. In contrast, no significant difference of SPIDER- $\beta$ Gal fluorescence signal was observed between fresh and frozen tissues. In conclusion, although imaging of fresh samples at $37^{\circ} \mathrm{C}$ is the best condition for both probes, successful imaging with gGlu-HMRG could be achieved even at room temperature with thawed samples. We demonstrate that temperature regulation and tissue handling of resected tissue are two pitfalls that may influence ex vivo imaging signals with enzyme-activatable fluorescent probes.

\section{INTRODUCTION}

Intraoperative optical fluorescence molecular imaging provides real-time image guidance to surgeons to identify precise tumor margins and detect tiny tumor foci both of which result in improved resections with less residual disease, decreasing the risk of recurrence [1]. Fluorescence imaging is low-cost and portable, yet highly sensitive and minimally invasive and does not utilize ionizing radiation [2-5]. Conventional imaging probes, called "always-on" probes, continuously emit signals similar to conventional contrast agents used in computed tomography (CT), magnetic resonance imaging (MRI), and angiography and the images depend on the biodistribution of the probe, resulting in relatively high background signals and requiring time to wash out the background signal from the body. In order to overcome this limitation, "activatable" probes have been introduced. They are turned on only after binding to a specific target found on tumors and, as a result, maximize the target 
signal while minimizing the background signal, resulting in a high target to background ratio (TBR) [6-8].

Small molecule enzyme-activatable fluorescence probes are rapidly cleaved and activated by a single enzymatic reaction using targeted endopeptidases. Often this process occurs in less than an hour making it practical for clinical translation $[9,10]$. Activatable probes have been investigated in preclinical animal models and some of them have recently proceeded to clinical trials [1113]. Such probes can target cancer-associated enzymes including cathepsin- $\mathrm{B}$, cathepsin- $\mathrm{L}[14,15]$, matrix metalloproteinases-2 (MMP-2) [16, 17], $\beta$-galactosidase ( $\beta$-Gal) [18-20] and $\gamma$-glutamyltransferase (GGT) (Figure 1) [9, 21, 22]. In some cases small molecule enzyme-activatable probes can be applied topically during surgery and can be rapidly activated, thus causing minimal disruption to workflow.

Determining the positivity of tumor margins is often important to achieve optimal surgical results. Thus, during surgery, intraoperative frozen section analysis (IFSA) is frequently performed to assess resection margins. However, IFSA is a labor-intensive technique and requires both cost and time during which the patient remains under anesthesia [23, 24]. IFSA can add more than 30 min to a surgical procedure $[25,26]$. Moreover, it can be limited by artifacts and undersampling, increasing the possibility of false negative results $[23,24]$. In comparison, the topical application of a rapidly acting enzyme-reactive probe to extracted specimens could provide a rapid and easy assessment of tumor margin.

$\beta$-Gal and GGT are overexpressed in a variety of cancers, and are potential candidates for intraoperative enzyme activated probes. In a previous report, we described the fluorescence signal and the kinetics generated by HMRef- $\beta$ Gal and SPiDER- $\beta$ Gal both activated by $\beta$-galactosidase and gGlu-HMRG which is activated by GGT in ovarian cancer cell lines at $37^{\circ} \mathrm{C}$ [10]. HMRef$\beta \mathrm{Gal}$, the original probe [19], behaved with similar kinetics to gGlu-HMRG probe at this temperature although the fluorescence signal of HMRef- $\beta$ Gal was much lower than that of gGlu-HMRG. This led to the selection of SPiDER- $\beta$ Gal as the preferred $\beta$-galactosidase-activated probe. However, in reality such probes must function at temperatures less than $37^{\circ} \mathrm{C}$ and their performance under other temperature conditions is poorly understood.

In this study, we compared incubation temperature and tumor tissue handling (fresh or frozen then thawed) for probes targeting two enzymes, GGT and $\beta$-galactosidase. Specimen temperature could affect the ability to see tumor margins. Therefore, we investigated fluorescence signal

A

\section{gGlu-HMRG}
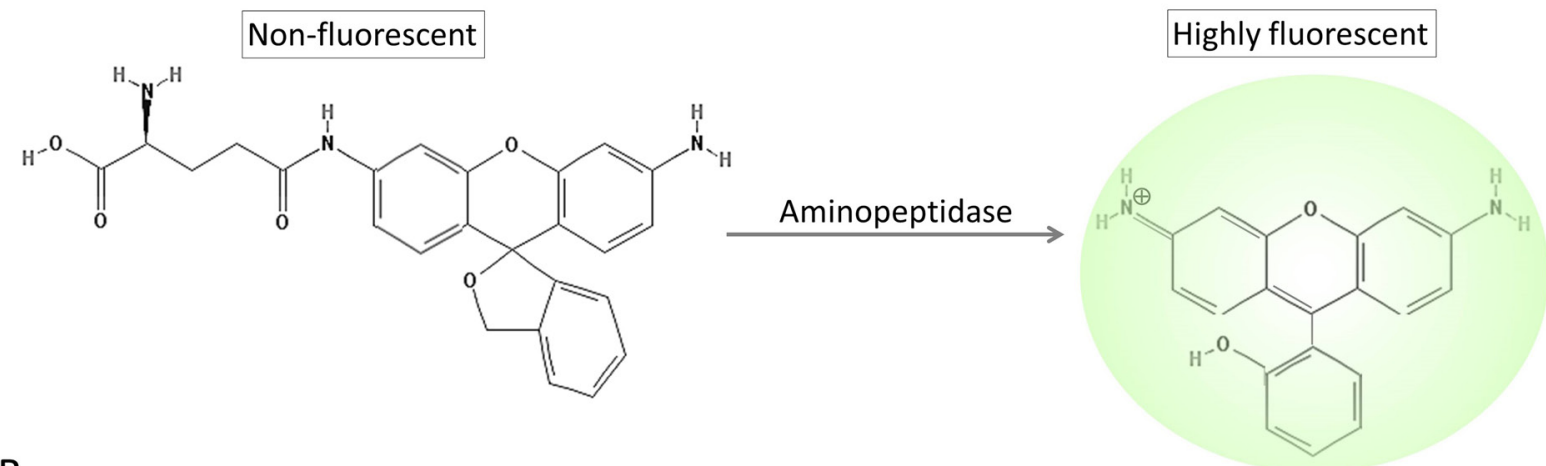

B SPIDER- $\beta$ Gal
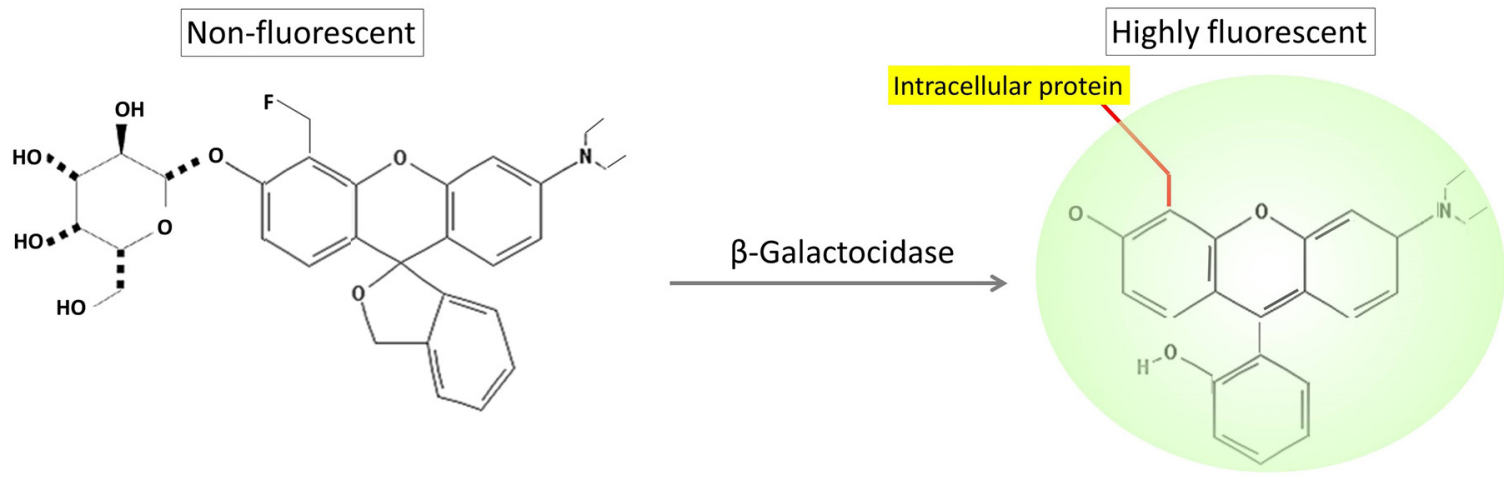

Intracellular stasis

Figure 1: Chemical structures of gGlu-HMRG (A) and SPiDER- $\beta$ Gal (B), and their enzymatic reaction with aminopeptidase and $\beta$-galactosidase. 
kinetics of gGlu-HMRG (Figure 1A) and SPiDER- $\beta$ Gal (Figure 1B) at different temperatures in in vitro and ex vivo imaging using cancer cell lines expressing the target enzyme.

\section{RESULTS}

\section{In vitro fluorescence imaging}

SHIN3 cells were serially observed under fluorescence microscopy up to 30 minutes after the addition of gGlu-HMRG or SPiDER- $\beta$ Gal. When the concentration of the probe or the temperature was higher, the fluorescence signals activated in cells were stronger (Figure 2). For cells incubated with $10 \mu \mathrm{M}$ of gGluHMRG, intracellular accumulation of the activated probes could be seen even at $4^{\circ} \mathrm{C}$. The florescence signal of SPiDER- $\beta$ Gal was significantly lower at $4^{\circ} \mathrm{C}$ and $22^{\circ} \mathrm{C}$ than that at $37^{\circ} \mathrm{C}$, suggesting that SPiDER- $\beta$ Gal was more sensitive to temperature than gGlu-HMRG.

\section{Persistence of fluorescence signal in vitro}

Flow cytometry analysis showed consistent results with the microscopic analysis. The gGlu-HMRG group showed statistically significantly higher fluorescence signals compared to SPiDER- $\beta$ Gal at all concentrations or temperatures. gGlu-HMRG was activated and detected even at $4^{\circ} \mathrm{C}$, whereas fluorescence signal of SPiDER$\beta \mathrm{Gal}$ was not detected at $4^{\circ} \mathrm{C}$ (Figure $3 \mathrm{~A}$ ). The relative mean fluorescence intensity (MFI) of the gGlu-HMRG group was also statistically higher compared to that of the SPiDER- $\beta$ Gal group regardless of concentration $(p<$ 0.05 ). Additionally, there was no statistically significant difference between fluorescence at $22^{\circ} \mathrm{C}$ and $37^{\circ} \mathrm{C}$ in the gGlu-HMRG group (Figure 3B).

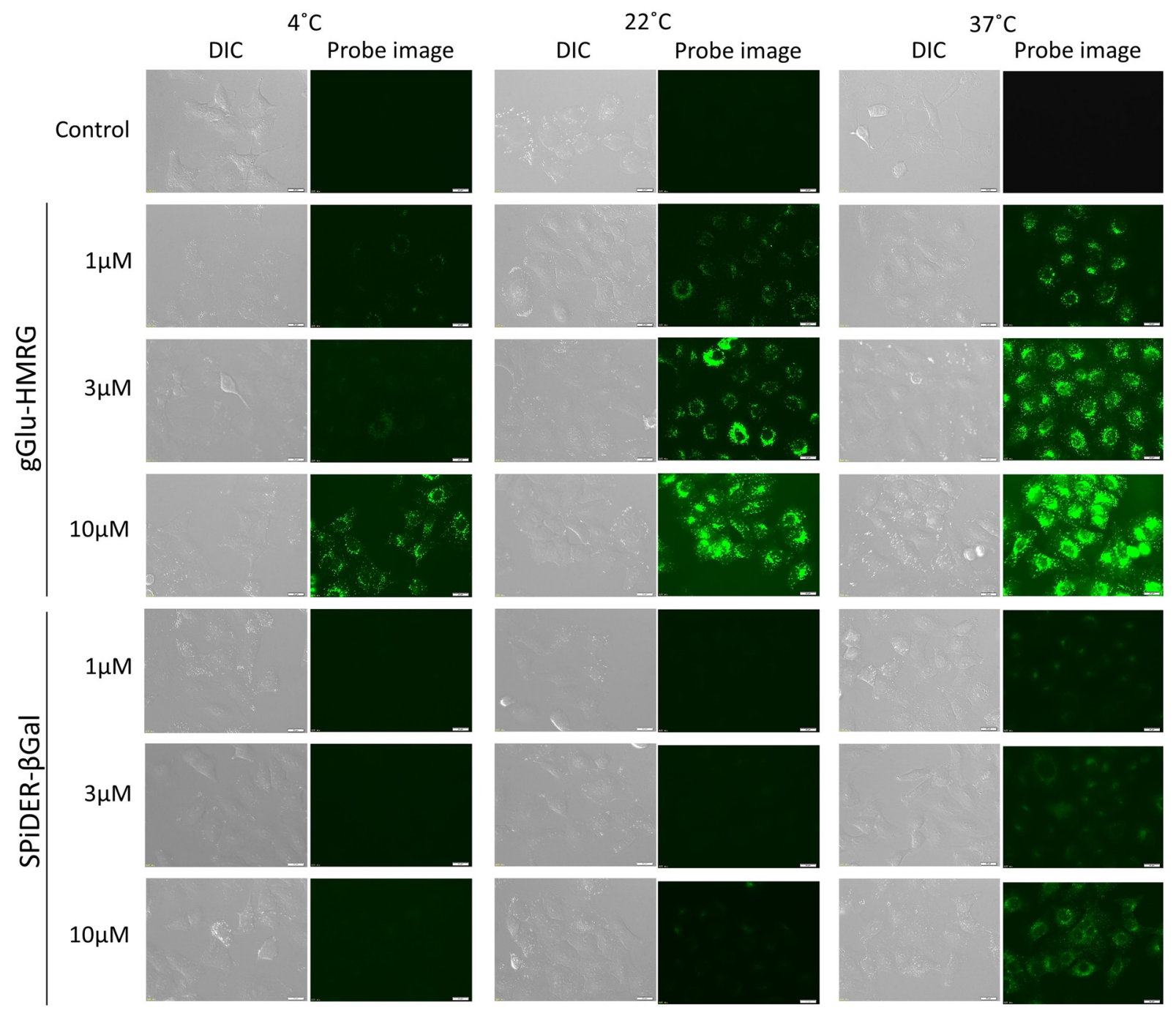

Figure 2: Fluorescence microscopic studies. SHIN3 cells were incubated with $1 \mu \mathrm{M}, 3 \mu \mathrm{M}$, and $10 \mu \mathrm{M}$ gGlu-HMRG or SPiDER- $\beta$ Gal for $10 \mathrm{~min}$ at $4{ }^{\circ} \mathrm{C}, 22^{\circ} \mathrm{C}$, and $37^{\circ} \mathrm{C}$. Camera setting: excitation wavelength range is $450-490 \mathrm{~nm}$ and emission wavelength range is $500-$ $550 \mathrm{~nm}$. Exposure time: $1000 \mathrm{~ms}$. Bars are $20 \mu \mathrm{m}$. 


\section{Ex vivo activatable imaging of fresh and frozen tumors}

The effect of temperature on fluorescence activation of both probes in fresh and frozen specimens was examined and quantitatively assessed on acquired images (Figure 4). In the fresh specimens after gGluHMRG or SPiDER- $\beta$ Gal was sprayed on the tissue, higher temperature yielded stronger fluorescence signal in both groups. The fluorescence intensity at $22^{\circ} \mathrm{C}$ in the gGluHMRG group was similar to that obtained at $37^{\circ} \mathrm{C}$ in the SPiDER- $\beta$ Gal group. The fluorescence intensity at $4^{\circ} \mathrm{C}$ with gGlu-HMRG and that at $4^{\circ} \mathrm{C}$ and $22^{\circ} \mathrm{C}$ with SPiDER$\beta \mathrm{Gal}$ was so low that tumor margins were invisible during the entire observation period (Figure 4A and 4C). In frozen specimens, both probes at $37^{\circ} \mathrm{C}$ showed clear margins within 20 minutes. The specimens with SPiDER- $\beta$ Gal at $22^{\circ} \mathrm{C}$ or with both probes at $4^{\circ} \mathrm{C}$ showed low fluorescence signals and unclear margins even at 30 minutes (Figure 4B and 4D).

\section{DISCUSSION}

Enzymes are proteins that act as catalysts in biological and pathological processes. Activity of enzymes is generally altered by temperature, which was seen in in vitro studies [27]. Hydrolytic activity of GGT and $\beta$-galactosidase is maximal at around $37^{\circ} \mathrm{C}$ or body temperature, then gradually decreases as temperature decreases [28]. Since the temperature of resected tissues quickly falls after removal from the body, investigating the temperature dependence of these probes is critical to optimizing their use for detecting tumor margins. After the application of gGlu-HMRG the extracted specimens showed high fluorescence signals and clear margins
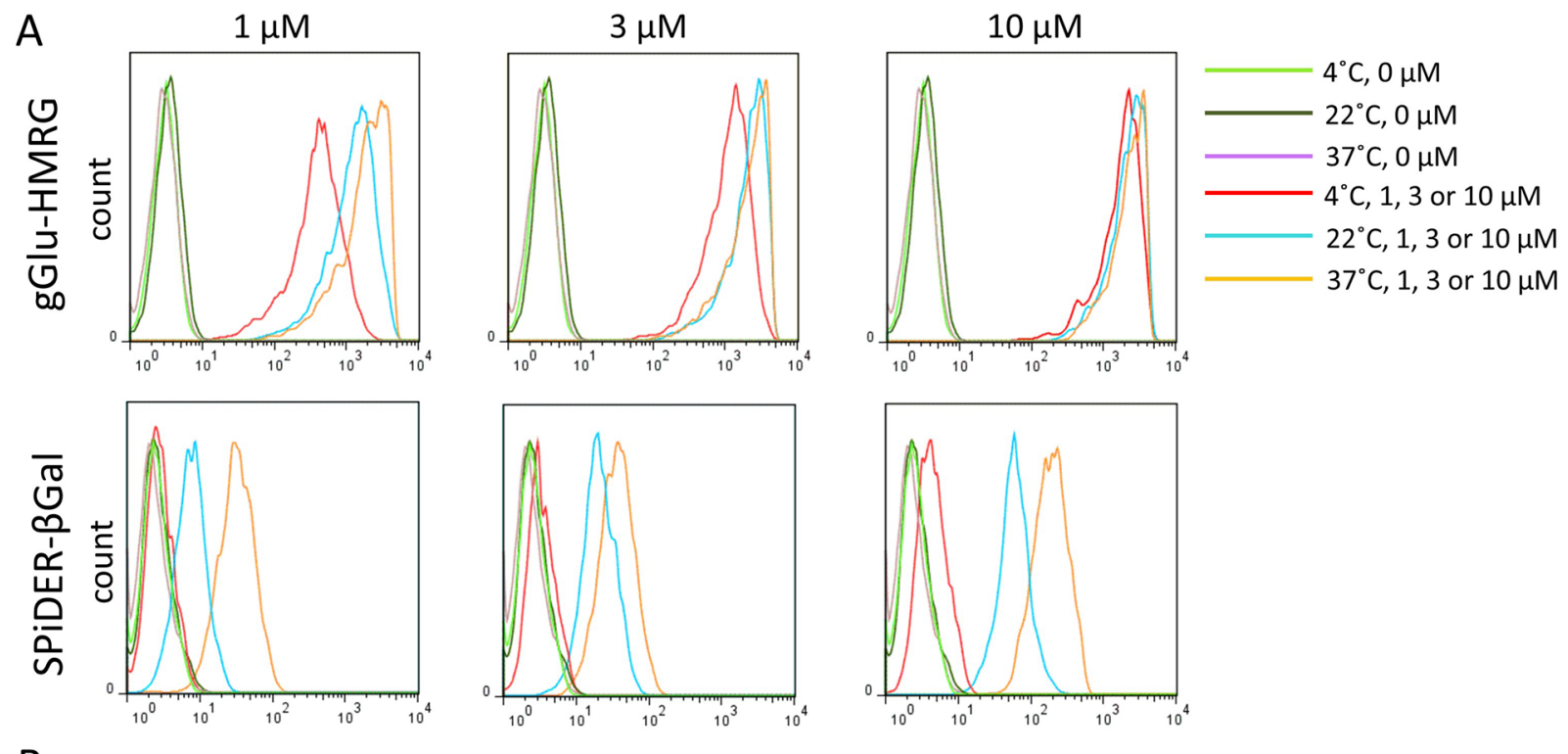

B
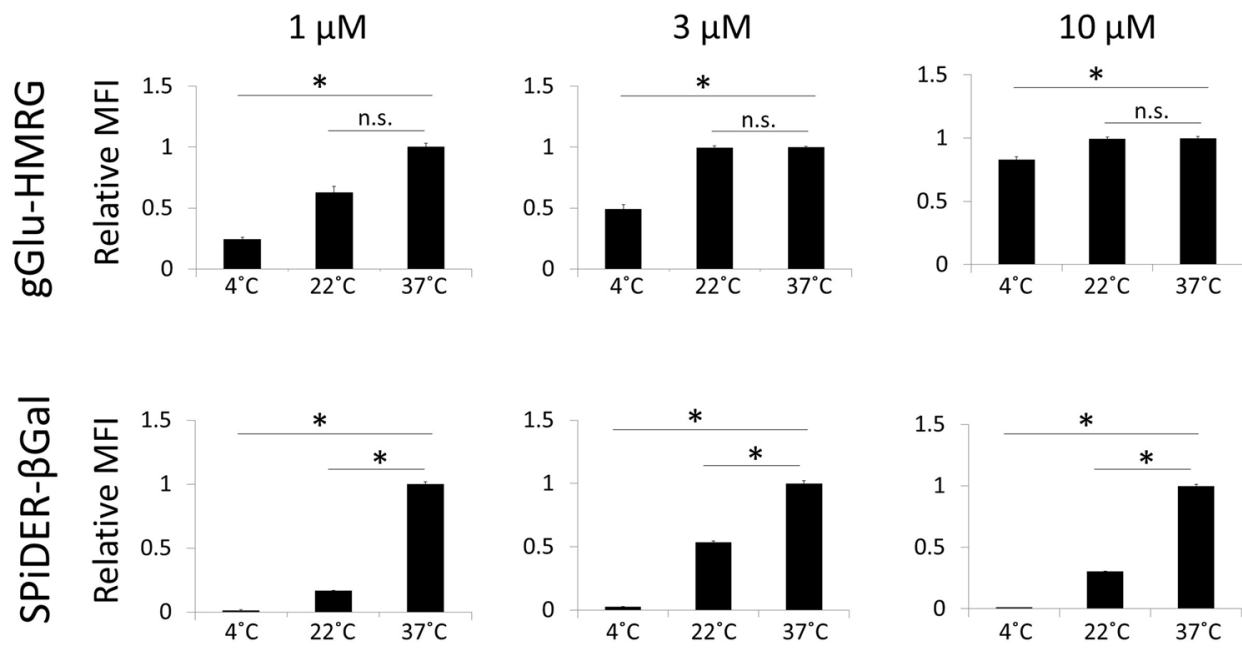

Figure 3: (A) Flow cytometric analysis. One representative individual is shown. (B) Relative MFI of gGlu-HMRG and SPiDER- $\beta$ Gal in SHIN3 cells. Asterisks show statistical significance of relative MFI between different temperatures. ( $\mathrm{n}=6$ in each group). 
even at $22^{\circ} \mathrm{C}$ that was comparable to the results with SPiDER- $\beta$ Gal at $37^{\circ} \mathrm{C}$. The activity of $\beta$-galactosidase at low temperature is known to be compromised [29, $30]$, therefore, it was not surprising that the fluorescence signal of SPiDER- $\beta$ Gal was insufficient to produce visible margins even at room temperature. Therefore, ex vivo imaging of resected specimens at room temperature is possible for gGlu-HMRG, but successful use of SPiDER$\beta \mathrm{Gal}$ requires that the specimens be heated close to body temperature.

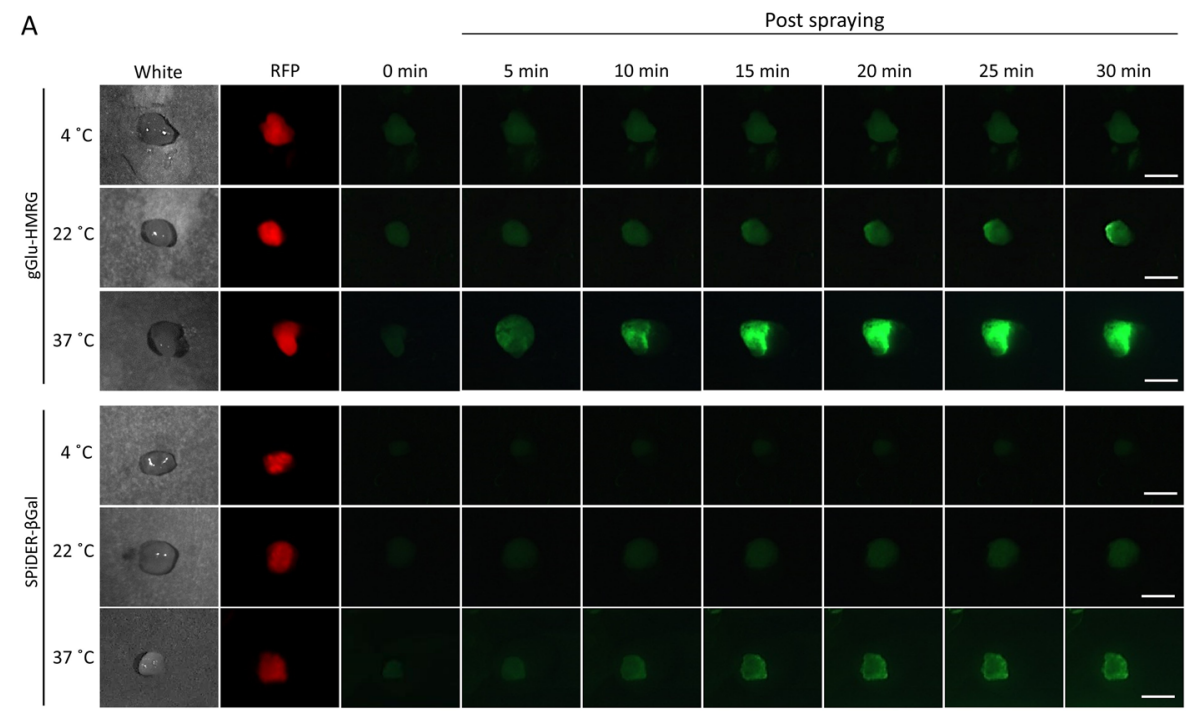

B

Post spraying
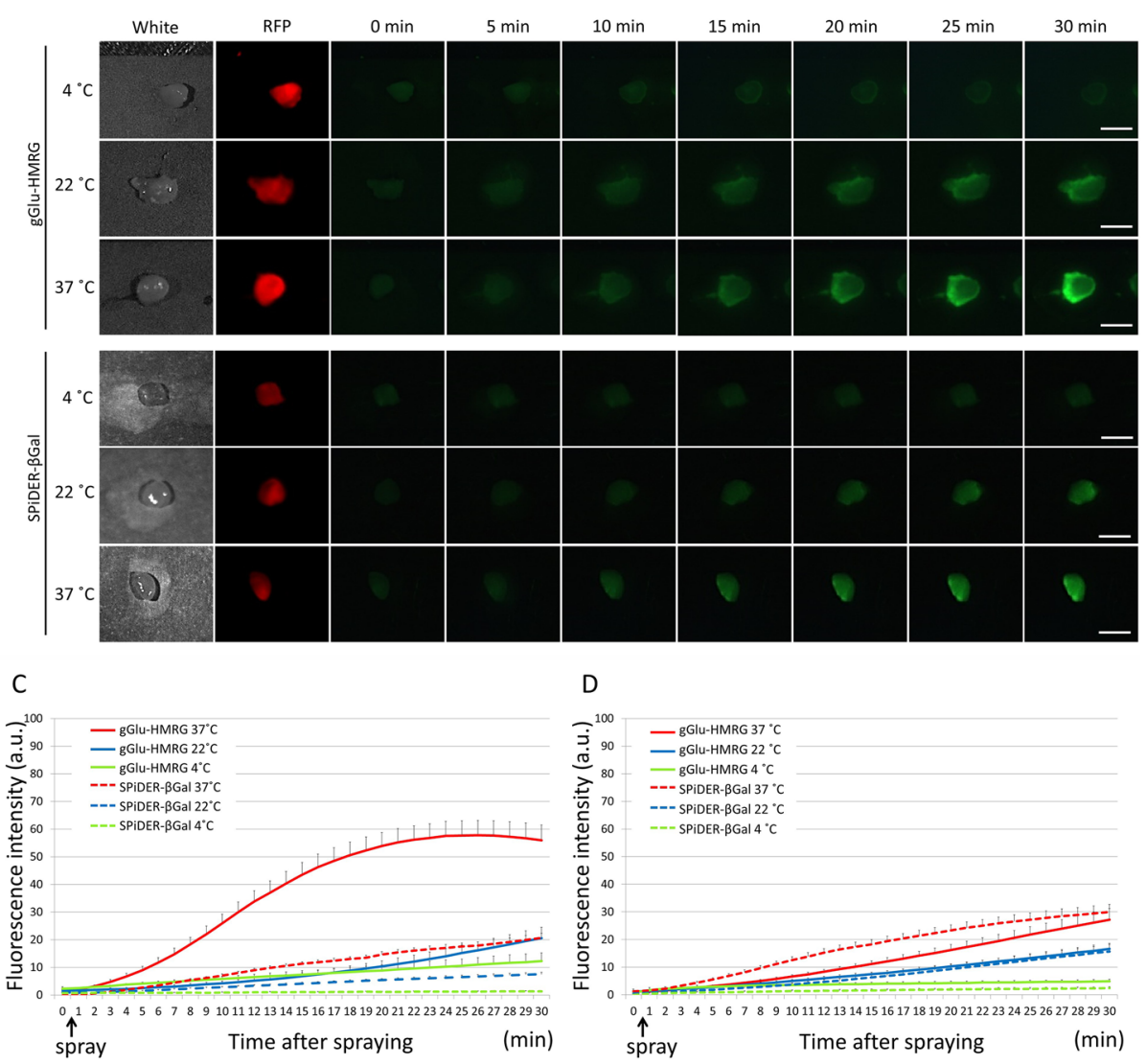

Figure 4: Fluorescence images after the probe is sprayed on the extracted tumor. Sequential fluorescence for 30 min, starting from just after spraying with $10 \mu \mathrm{M}$ gGlu-HMRG and $50 \mu \mathrm{M}$ SPiDER- $\beta \mathrm{Gal}$ at $4{ }^{\circ} \mathrm{C}, 22^{\circ} \mathrm{C}$, and $37^{\circ} \mathrm{C}$ in fresh specimens (A) and frozen specimens (B). Time fluorescence intensity of the extracted tumors after spraying for fresh tumors (C) and frozen then thawed tumors (D) are shown. Data are mean fluorescence intensities \pm SEM of tumors at different time points $(\mathrm{n}=9$ in each group). Bars are $5 \mathrm{~mm}$. 
We observed that freshly-extracted specimens incubated with gGlu-HMRG showed significant fluorescence intensity even at $22^{\circ} \mathrm{C}$, suggesting that the tumor margin could be easily detected in the operation room. SPiDER- $\beta$ gal at $37^{\circ} \mathrm{C}$ was comparable to that of gGlu-HMRG at $22^{\circ} \mathrm{C}$ for both fresh and thawed specimens, suggesting that the use of SPiDER- $\beta$ Gal requires the tissue to be brought to a temperature of $37^{\circ} \mathrm{C}$. Compared to fresh specimens, thawed specimens showed low fluorescence intensity after the topical application of gGlu-HMRG. After reacting with GGT on the cell surface, gGlu-HMRG releases HMRG, which is the activated and fluorescent form of the probe, which internalizes into cells using both active and passive transport and eventually accumulating in the lysosome due to its acidic $\mathrm{pH}$ condition. The process of freezing and thawing reduces active transport functions and may increase $\mathrm{pH}$ in the lysosome that could compromise the accumulation of HMRG in the lysosome. On the other hand, frozen then thawed specimens sprayed with SPiDER- $\beta$ Gal showed comparable or even higher fluorescence signal than fresh specimens. This may be due to freeze-thaw induced membrane damage with increased permeability and stabilization of the activated form SPiDER- $\beta$ Gal to intracellular proteins [10]. With either probe, although frozen tissue can be thawed and analyzed, temperature control is even more crucial than with fresh specimens. Taken together, a probe which is trapped in cells by a chemical linkage such as SPiDER- $\beta$ Gal yields similar fluorescence signal regardless of freshness of tissue samples. In contrast, fluorescence signal intensity of a probe which is trapped in cells depending on physiological $\mathrm{pH}$ such as gGlu-HMRG greatly relies on freshness of tissue samples.

In conclusion, although imaging of fresh samples at $37^{\circ} \mathrm{C}$ is the best condition for both probes, successful imaging with gGlu-HMRG can be achieved even at room temperature with thawed samples. A sprayable enzymeactivatable fluorescence probe such as gGlu-HMRG will not only be applied for fluorescence-guided surgery in vivo, but also supplement IFSA to evaluate the border of invasive cancer on resected ex vivo specimens under optimized temperature conditions.

\section{MATERIALS AND METHODS}

\section{Reagents}

gGlu-HMRG, a GGT-activated fluorescent probe, was synthesized as described previously [9]. GGT is a cell surface enzyme involved in extracellular glutathione metabolism and drug resistance, as well as in leukotriene catabolism [31, 32]. SPiDER- $\beta$ Gal was obtained from Dojindo Molecular Technologies, Inc. (Rockville, MD, USA) [20]. $\beta$-galactosidase catalyzes the hydrolysis of lactose into glucose and galactose.

\section{Cell lines and culture}

An established human ovarian cancer cell line, SHIN3, was used for in vitro fluorescence microscopy and flow cytometry. High expression of GGT and high expression of $\beta$-galactosidase have been reported in SHIN3 [9, 19]. SHIN3 cells were transfected with a plasmid expressing red fluorescent protein (RFP) to create a red fluorescent phenotype (SHIN3-RFP), as previously described [33] and were used for ex vivo tumor imaging. Cell lines were grown in RPMI 1640 medium (Life Technologies, Gaithersburg, MD, USA) supplemented with $10 \%$ fetal bovine serum (FBS) (Life Technologies) and $1 \%$ penicillin-streptomycin (Life Technologies) in tissue culture flasks in a humidified incubator at $37^{\circ} \mathrm{C}$ in $5 \%$ carbon dioxide.

\section{Fluorescence microscopy analysis}

$1 \times 10^{5}$ cells from each cell line were plated on a culture well covered by a glass-cover slip and incubated in culture medium for $24 \mathrm{~h}$. Both temperature and probe concentration were tested for fluorescence intensity. gGlu-HMRG or SPiDER- $\beta$ Gal $(1 \mu \mathrm{M}, 3 \mu \mathrm{M}$ and $10 \mu \mathrm{M})$ was added to the culture medium and incubated for 30 min at three temperature variations, $4{ }^{\circ} \mathrm{C}, 22^{\circ} \mathrm{C}$ (room temperature) or $37^{\circ} \mathrm{C}$. After incubation, cells were washed once with phosphate buffered saline (PBS). Fluorescence microscopy was performed using an Olympus BX61 microscope (Olympus America, Inc., Melville, NY) equipped with the following filters: excitation wavelength range 450-490 $\mathrm{nm}$ and emission wavelength range 500$550 \mathrm{~nm}$. Transmitted light differential interference contrast (DIC) images were also acquired.

\section{Flow cytometric analysis}

SHIN3 cells $\left(1 \times 10^{6}\right)$ were plated in a 24 -chamber culture well and incubated for $24 \mathrm{~h}$. After $1 \mu \mathrm{M}, 3 \mu \mathrm{M}$, or $10 \mu \mathrm{M}$ of gGlu-HMRG or SPiDER-bGal was added to the culture medium, cells were incubated for $30 \mathrm{~min}$ at three different temperature conditions: $4{ }^{\circ} \mathrm{C}, 22^{\circ} \mathrm{C}$ (room temperature) or $37^{\circ} \mathrm{C}$. After incubation, cells were washed once with PBS, quickly scraped, and suspended in FACS buffer (PBS supplemented with 5\% FBS) on ice. Propidium iodide (PI)-positive dead cells were gated out and the remaining cells were analyzed using a FACS Calibur (BD BioSciences, San Jose, CA, USA). Relative MFI was quantified as the ratio of MFI at each temperature to MFI at $37^{\circ} \mathrm{C}$ using CellQuest software (BD BioScience, San Jose, USA).

\section{Tumor model}

All in vivo procedures were conducted in compliance with the Guide for the Care and Use of Laboratory Animal Resources (1996), US National Research Council, and 
approved by the local Animal Care and Use Committee. Eight-week-old female homozygote athymic nude mice were purchased from Charles River (NCI, Frederick, MD). SHIN3-RFP cells $\left(2 \times 10^{6}\right)$ suspended in $200 \mu \mathrm{L}$ of PBS was subcutaneously injected in the right and left dorsi of mice. Experiments with tumor-bearing mice were performed 14 days after injection of the cells.

\section{Ex vivo fluorescence imaging of fresh and frozen tumors}

Mice with tumors were euthanized by carbon dioxide inhalation and the subcutaneous tumors were immediately extracted. In order to examine the effect of temperature on enzyme activity, the probe was sprayed on fresh SHIN3-RFP tumors at three different temperatures, $4^{\circ} \mathrm{C}, 22^{\circ} \mathrm{C}$ and $37^{\circ} \mathrm{C}$. Furthermore, another set of tumors was temporarily frozen in liquid nitrogen and thawed at $4^{\circ} \mathrm{C}, 22^{\circ} \mathrm{C}$ and $37^{\circ} \mathrm{C}$. Diluted aqueous solutions $(300 \mu \mathrm{L})$ of gGlu-HMRG $(10 \mu \mathrm{M})$ or SPiDER- $\beta$ Gal $(50 \mu \mathrm{M})$ in PBS were dropped on the extracted tumor ( $\mathrm{n}=9$ in each group). Imaging for the group at $4^{\circ} \mathrm{C}$ was performed on ice and the group at $37^{\circ} \mathrm{C}$ was on a heating pad. The temperature of specimens was confirmed by a thermal camera (FLIR C2, FLIR Systems, Inc., Wilsonville, OR, USA) before spraying. Serial fluorescence imaging was recorded every minute for $30 \mathrm{~min}$ using a portable fluorescence camera (Discovery INDEC BioSystems, Santa Clara, CA, USA) [34] with the following filter set: band-pass filter from 450 to $490 \mathrm{~nm}$ for excitation light and from 511 to $551 \mathrm{~nm}$ for emission light, with an exposure time of $50 \mathrm{msec}$. RFP images were used as a reference for optical identification of SHIN3 cells with the Maestro In-Vivo Imaging System (Cri, Woburn, MA, USA). The following filter set was used: a band-path filter from 503 to $555 \mathrm{~nm}$ for excitation light and a long-pass filter over $645 \mathrm{~nm}$ for emission light. The tunable emission filter was automatically stepped in $10 \mathrm{~nm}$ increments from 600 to $800 \mathrm{~nm}$ at constant exposure times. The spectral fluorescence images consisting of spectra from autofluorescence and RFP were then unmixed, based on their known spectral patterns using commercial software (Maestro software; CRi). Regions of interest (ROIs) were drawn within the tumor nodules depicted by the RFP images and then the average fluorescence intensity of each ROI was measured. Fluorescence intensity ratio was calculated from the average fluorescence intensity at each time point divided by that at baseline. All fluorescence images were analyzed with ImageJ software (http://rsb.info.nih.gov/ij/).

\section{Statistical analysis}

Comparisons between two groups were made using Student's t-test (2-tailed). Differences among more than two groups were analyzed using one-way ANOVA followed by post hoc Bonferroni (3 groups) or Tukey-
Kramer ( $>3$ groups) tests. Values of p less than 0.05 were considered significant. Error bars represent standard error of the mean (SEM).

\section{Abbreviations}

gGlu-HMRG: $\gamma$-glutamyl hydroxymethyl rhodamine green; CT: computed tomography; MRI: magnetic resonance imaging; MMP-2: matrix metalloproteinases-2; $\beta$-Gal: $\beta$-galactosidase; GGT: $\gamma$-glutamyltransferase; IFSA: intraoperative frozen section analysis; RFP: red fluorescent protein; PBS: phosphate buffered saline; DIC: differential interference contrast; PI: propidium iodide; MFI: mean fluorescence intensity; ROI: region of interest; SEM: standard error of the mean.

\section{Author contributions}

A.M., F.O., and H.K. conceptualized and designed the study. A.M. and F.O. performed the experiments. A.M., F.O., and H.K. performed data analysis and interpretation and drafted the initial manuscript. P.L.C. and H.K. edited and wrote the final version of manuscript. Y.M., T.N., R.O., F.I., and D.F. prepared the experiments and contributed to data collection and interpretation. All authors critically reviewed manuscript and approved the final version of the manuscript.

\section{CONFLICTS OF INTEREST}

The authors declare no competing financial interests.

\section{FUNDING}

This research was supported by the Intramural Research Program of the National Institutes of Health, National Cancer Institute, Center for Cancer Research (ZIA-BC011512).

\section{REFERENCES}

1. Nguyen QT, Tsien RY. Fluorescence-guided surgery with live molecular navigation--a new cutting edge. Nat Rev Cancer. 2013; 13:653-662.

2. Kobayashi H, Ogawa M, Alford R, Choyke PL, Urano Y. New strategies for fluorescent probe design in medical diagnostic imaging. Chem Rev. 2010; 110:2620-2640.

3. Keereweer S, Kerrebijn JD, van Driel PB, Xie B, Kaijzel EL, Snoeks TJ, Que I, Hutteman M, van der Vorst JR, Mieog JS, Vahrmeijer AL, van de Velde CJ, Baatenburg de Jong RJ, Löwik CW. Optical image-guided surgery-where do we stand? Mol Imaging Biol. 2011; 13:199-207.

4. Nagaya T, Nakamura YA, Choyke PL, Kobayashi H. Fluorescence-Guided Surgery. Front Oncol. 2017; 7:314. 
5. Zhang RR, Schroeder AB, Grudzinski JJ, Rosenthal EL, Warram JM, Pinchuk AN, Eliceiri KW, Kuo JS, Weichert JP. Beyond the margins: real-time detection of cancer using targeted fluorophores. Nat Rev Clin Oncol. 2017; 14:347-364.

6. Ogawa M, Kosaka N, Choyke PL, Kobayashi H. In vivo molecular imaging of cancer with a quenching nearinfrared fluorescent probe using conjugates of monoclonal antibodies and indocyanine green. Cancer Res. 2009; 69:1268-1272.

7. Kobayashi H, Choyke PL. Target-cancer-cell-specific activatable fluorescence imaging probes: rational design and in vivo applications. Acc Chem Res. 2011; 44:83-90.

8. Urano Y. Novel live imaging techniques of cellular functions and in vivo tumors based on precise design of small molecule-based 'activatable' fluorescence probes. Curr Opin Chem Biol. 2012; 16:602-608.

9. Urano Y, Sakabe M, Kosaka N, Ogawa M, Mitsunaga M, Asanuma D, Kamiya M, Young MR, Nagano T, Choyke PL, Kobayashi H. Rapid cancer detection by topically spraying a gamma-glutamyltranspeptidase-activated fluorescent probe. Sci Transl Med. 2011; 3:110ra119.

10. Nakamura Y, Mochida A, Nagaya T, Okuyama S, Ogata F, Choyke PL, Kobayashi H. A topically-sprayable, activatable fluorescent and retaining probe, SPiDER-betaGal for detecting cancer: Advantages of anchoring to cellular proteins after activation. Oncotarget. 2017; 8:39512-39521. https://doi.org/10.18632/oncotarget.17080.

11. Savariar EN, Felsen CN, Nashi N, Jiang T, Ellies LG, Steinbach P, Tsien RY, Nguyen QT. Real-time in vivo molecular detection of primary tumors and metastases with ratiometric activatable cell-penetrating peptides. Cancer Res. 2013; 73:855-864.

12. Whitley MJ, Cardona DM, Lazarides AL, Spasojevic I, Ferrer JM, Cahill J, Lee CL, Snuderl M, Blazer DG 3rd, Hwang ES, Greenup RA, Mosca PJ, Mito JK, et al. A mouse-human phase 1 co-clinical trial of a proteaseactivated fluorescent probe for imaging cancer. Sci Transl Med. 2016; 8:320ra324.

13. Miampamba M, Liu J, Harootunian A, Gale AJ, Baird S, Chen SL, Nguyen QT, Tsien RY, Gonzalez JE. Sensitive in vivo Visualization of Breast Cancer Using Ratiometric Protease-activatable Fluorescent Imaging Agent, AVB-620. Theranostics. 2017; 7:3369-3386.

14. Tung $\mathrm{CH}$, Bredow S, Mahmood U, Weissleder R. Preparation of a cathepsin D sensitive near-infrared fluorescence probe for imaging. Bioconjug Chem. 1999; 10:892-896.

15. Tung $\mathrm{CH}$, Mahmood U, Bredow $\mathrm{S}$, Weissleder R. In vivo imaging of proteolytic enzyme activity using a novel molecular reporter. Cancer Res. 2000; 60:4953-4958.

16. Bremer C, Bredow S, Mahmood U, Weissleder R, Tung $\mathrm{CH}$. Optical imaging of matrix metalloproteinase-2 activity in tumors: feasibility study in a mouse model. Radiology. 2001; 221:523-529.
17. Lebel R, Lepage M. A comprehensive review on controls in molecular imaging: lessons from MMP-2 imaging. Contrast Media Mol Imaging. 2014; 9:187-210.

18. Kamiya M, Asanuma D, Kuranaga E, Takeishi A, Sakabe M, Miura M, Nagano T, Urano Y. $\beta$-Galactosidase fluorescence probe with improved cellular accumulation based on a spirocyclized rhodol scaffold. J Am Chem Soc. 2011; 133:12960-12963.

19. Asanuma D, Sakabe M, Kamiya M, Yamamoto K, Hiratake J, Ogawa M, Kosaka N, Choyke PL, Nagano T, Kobayashi H, Urano Y. Sensitive beta-galactosidasetargeting fluorescence probe for visualizing small peritoneal metastatic tumours in vivo. Nat Commun. 2015; 6:6463.

20. Doura T, Kamiya M, Obata F, Yamaguchi Y, Hiyama TY, Matsuda T, Fukamizu A, Noda M, Miura M, Urano Y. Detection of LacZ-Positive Cells in Living Tissue with Single-Cell Resolution. Angew Chem Int Ed Engl. 2016; 55:9620-9624.

21. Chatterjee SK, Bhattacharya M, Barlow JJ. Glycosyltransferase and glycosidase activities in ovarian cancer patients. Cancer Res. 1979; 39:1943-1951.

22. Razgulin A, Ma N, Rao J. Strategies for in vivo imaging of enzyme activity: an overview and recent advances. Chem Soc Rev. 2011; 40:4186-4216.

23. Fukamachi K, Ishida T, Usami S, Takeda M, Watanabe M, Sasano H, Ohuchi N. Total-circumference intraoperative frozen section analysis reduces margin-positive rate in breast-conservation surgery. Jpn J Clin Oncol. 2010; 40:513-520.

24. Ueo H, Shinden Y, Tobo T, Gamachi A, Udo M, Komatsu H, Nambara S, Saito T, Ueda M, Hirata H, Sakimura S, Takano Y, Uchi R, et al. Rapid intraoperative visualization of breast lesions with gamma-glutamyl hydroxymethyl rhodamine green. Sci Rep. 2015; 5:12080.

25. Esbona K, Li Z, Wilke LG. Intraoperative imprint cytology and frozen section pathology for margin assessment in breast conservation surgery: a systematic review. Ann Surg Oncol. 2012; 19:3236-3245.

26. Hussain T, Nguyen QT. Molecular imaging for cancer diagnosis and surgery. Adv Drug Deliv Rev. 2014; 66:90-100.

27. Choi KY, Swierczewska M, Lee S, Chen X. Proteaseactivated drug development. Theranostics. 2012; 2:156-178.

28. More N, Daniel RM, Petach HH. The effect of low temperatures on enzyme activity. Biochem J. 1995; 305:17-20.

29. Trimbur DE, Gutshall KR, Prema P, Brenchley JE. Characterization of a psychrotrophic Arthrobacter gene and its cold-active beta-galactosidase. Appl Environ Microbiol. 1994; 60:4544-4552.

30. Wang GX, Gao Y, Hu B, Lu XL, Liu XY, Jiao BH. A novel cold-adapted beta-galactosidase isolated from Halomonas sp. S62: gene cloning, purification and enzymatic characterization. World J Microbiol Biotechnol. 2013; 29:1473-1480. 
31. Wickham S, West MB, Cook PF, Hanigan MH. Gammaglutamyl compounds: substrate specificity of gammaglutamyl transpeptidase enzymes. Anal Biochem. 2011; 414:208-214.

32. Hanigan MH. Gamma-glutamyl transpeptidase: redox regulation and drug resistance. Adv Cancer Res. 2014; 122:103-141.

33. Hama Y, Urano Y, Koyama Y, Kamiya M, Bernardo M, Paik RS, Shin IS, Paik CH, Choyke PL, Kobayashi H. A target cell-specific activatable fluorescence probe for in vivo molecular imaging of cancer based on a self-quenched avidin-rhodamine conjugate. Cancer Res. 2007; 67:2791-2799.

34. Kakareka JW, McCann TE, Kosaka N, Mitsunaga M, Morgan NY, Pohida TJ, Choyke PL, Kobayashi H. A portable fluorescence camera for testing surgical specimens in the operating room: description and early evaluation. Mol Imaging Biol. 2011; 13:862-867. 